\title{
Research on Modes of Cargo Ro-Ro, Drop and Pull Transport in Land-Sea Transportation Channel between Shandong and Liaoning
}

\author{
Yongsheng Liu, Yu Li, Juan Chen \\ Graduate School, Beijing Wuzi University, Beijing, China \\ Email: bjwylys@sina.com
}

Received 9 March 2015; accepted 6 April 2015; published 9 April 2015

Copyright (C) 2015 by authors and Scientific Research Publishing Inc.

This work is licensed under the Creative Commons Attribution International License (CC BY). http://creativecommons.org/licenses/by/4.0/

\section{(c) (i) Open Access}

\begin{abstract}
In order to accelerate national industrial upgrading of transportation and deepen the development of logistics industry, it is imperative to construct the land-sea transportation channel between Shandong and Liaoning provinces. Taking practical situations of the two places into account, the paper aims to investigate the application of $\mathrm{M}$ to $\mathrm{N}$ mode in the process of cargo roll on-roll off, drop and pull transport and then elaborate the site selection issue of drop and pull centers from the perspective of P-median model. Meanwhile, the paper proposes to adopt "south bridging-north rolling" concept to build a brand new transportation channel which combines the cross-sea bridge with ro-ro ferry concerning the natural conditions in Bohai Bay. Corresponding solution to each project will be put forward at last.
\end{abstract}

\section{Keywords}

Land-Sea Transportation Channel, Roll on-Roll off Transport, Drop and Pull Transport Pattern, Cross-Sea Bridge

\section{Introduction}

The Twelfth Five-Year Plan period is critical for national transportation industry's shift of development pattern, which requires the national energy conservation and emission reduction strategy to be implemented, logistics industry's development level to be promoted while enhancing development quality at the same time. The landsea transportation channel between Shandong and Liaoning is a gold intermodal transportation channel aiming 
to seek comprehensive, low-carbon and sustainable development in Bohai Bay, which integrates regional transportation resources into the promotion of regional economy's coordinated development. Taking Shandong, Liaoning as the endpoint, the channel relies on Weifang port and Yingkou port connecting Lu Liao Peninsula, thus facilitating market integration of the northeast and east China while serving east Mongolia, central and south China region as well. The idea that constructing the land-sea transportation channel between Shandong and Liaoning is an innovation on the exploration of organization modes of multimodal transport and drop and pull comprehensive transport, which conforms to the eighteen session of the Third Plenary Session's objective requirements on accelerating the transformation of economic development pattern as well as the construction of an innovation-oriented country. Meanwhile, it deepens the reform comprehensively by boosting economic efficiency, fairness and sustainable development, which is expected to become the largest sole energy conservation project in the field of domestic transportation, thus generating considerable ecological benefit. The construction of the channel will connect the integrated transportation system of east Mongolia-northeast area and Shandong Peninsula blue-economic zone while fueling the growth of supply and demands in the freight market, which is of high significance on promoting Bohai economic circle's development and the economic dealings among the northeast, northern China, east China, southern China and other regions.

Early in 2006, the waterborne department in Ministry of Transport has issued an announcement named Notice of the Study on Promoting the Use of Drop and Pull Transport Mode in the Process of Ro-Ro cargo Transport (Domestic Letter of Waterway [2006] No. 145). The project team organized by the water transport and highway departments has done a vast amount of research on the application of drop and pull transport to ro-ro cargo transport in Bohai Bay [1]. On the other hand, Several Opinions on Accelerating Developing Modern Transportation issued by Ministry of Transport in 2007 put forward gradually fulfilling freight's seamless connection, passenger transport's no transit and developing van transport, drop and pull transport and combination vehicles, thus enhancing transportation facilities' technical merit [2]. Yantai Salvage Bureau took the lead in carrying out drop and pull transport on ro-ro transport channel between Yantai and Dalian in 2007 by conducting experimental operations on the "Milky Way Prince" ferry. Yantai Luliao Drop and Pull Logistics Limited Company and Shandong Beiming Full Logistics Limited Company were founded then in 2008 [3]. Over the past six years, drop and pull transport has played an increasingly crucial role in linking up land and sea transportation and successfully led the way towards innovation of ro-ro cargo transport. The Bohai Gulf Drop and Pull Transport Union Conference (including Hebei, Tianjin, Inner Mongolia, Liaoning, Heilongjiang, Jilin and Shandong Provinces) was held in Yantai in 2012, during which Bohai Gulf Drop and Pull Transport Union Regulations was adopted. It highlights the significance of innovating collaborated operation pattern of drop and pull transport, realizing seamless connection of policy standards among areas and establishing regional operational network with the advantage of Bohai Bay's geography and hinterland [4]. At present there are 13 ship routes such as Dalian-Weihai, Dalian-Penglai and over 2500 load cars between Liaoning and Shandong, thus shaping the form characterized by main ro-ro transport stations consisting of Dalian port passenger station, Lvshun port office, Dalian port group, Yantai port passenger station, Weihai port passenger station and Penglai port passenger station, which have covered more than $80 \%$ of ro-ro routes and ferries and contributed to $90 \%$ of the traffic volume [5].

As can be seen from the above, cargo ro-ro, drop and pull transport in Bohai Bay has accumulated certain practical experience yet there still remain development bottleneck and problems like lagging restructuring and operational inefficiency. Investigating and studying the construction of the land-sea transportation channel between Shandong and Liaoning, therefore, are not only a moment for integrating comprehensive transportation resources in Bohai Bay, but a review of all previous practices, which is of high transitional historical significance.

\section{Briefing on the Concept}

Roll on-roll off cargo transport refers to the way of delivering goods along with forklifts, semitrailers or cars onto ro-ro ships and then going ashore by the loader vehicles after arriving at the destination. The appearance of ro-ro ships enables the cargo to be loaded and unloaded horizontally at the ship passage. As a result, assignments can be completed during the moving process through roller loading and unloading tools [6]. This kind of transportation applies to short-haul shipments among the enclosed sea, the bay, the strait and offshore islands in developed areas. The advantages of ro-ro transport includes high cargo handling rate, flexibility and convenient door to door services, which speeds up the turnover of ships and boosts port handling capacity. However, there 
are development bottlenecks such as safety loophole and ineffective freight houses’ utilization.

Drop and pull transport, namely drop and pull handling, refers to the way that motivated tractors drop the carrying device (including semitrailers, full trailers and containers) at one destination as planned while the cargo being hanged again on a new trailer and being transported to another destination [7]. Through the carrying device and the free combination and separation of tractors, drop and pull transport can adjust the demand towards relevant dispatch, thus improving transportation efficiency and saving the cost.

The fundamental flow path of cargo ro-ro, drop and pull transport in Bohai Bay can be generalized into the following three procedures. The first step is that tractors drop the trailer at the port of loading according to the plan. After assuring both the shipping list and security certificate are problem free, the trailer goes through the safety check and boards the ship. Meanwhile, the tractor waits on-site or pulls a new trailer towards another destination. The second procedure is that the trailer categorized by specifications is parked in the booked stall on the ro-ro ship and later is pulled by the trailer at the port of arrival going ashore. The third procedure is that the escorting driver boarding the ship rents the local tractor, through which drops the trailer to the port of destination or the freight station [8].

Taking the transport process from Dalian Port to Yantai Port for instance, the fundamental flow path of cargo ro-ro, drop and pull transportation is demonstrated in Figure 1.

\section{Investigation in Cargo Ro-Ro, Drop and Pull Transport Pattern}

\subsection{Analysis on Drop and Pull Transport Pattern}

Although Bohai Bay's ro-ro cargo transport has been advancing rapidly since 1990s counting on its geographic advantages, logistics companies remain "enormous, small and scattered" currently. Being restricted by enterprises' as well as drop and pull centers' scales, the transportation mode of connection on both sides combined with middle main line is difficult to be carried out [3]. On the basis of features of drop and pull transport and regional practical situation, $\mathrm{M}$ to $\mathrm{N}$ drop and pull pattern, which is separated into $\mathrm{M}$ to $\mathrm{N}$ drop and pull pattern by land and $\mathrm{M}$ to $\mathrm{N}$ drop and pull cross-sea connection pattern, can be adopted. On one hand, $\mathrm{M}$ to $\mathrm{N}$ drop and pull pattern by land refers to the application of drop and pull transport in ports' specialized transportation work zones in Shandong and Liaoning. $\mathrm{M}$ stands for the unfixed amount of motivated tractors while $\mathrm{N}$ represents the amount of different carrying device (such as trailers) pulled by the tractor in work zones during the cargo's drop and pull process. The concrete operation procedure can be elaborated as selecting drop and pull centers with the circumference of $5 \mathrm{~km}$ approaching the wharf or the port in Shandong and Liaoning respectively and then placing unloaded or loaded trailers in those centers. Tractors pull unloaded or loaded trailers towards the factory for cargo handling according to the degree of client demand emergency and return trailers to centers or the wharf later. On the other hand, $\mathrm{M}$ to $\mathrm{N}$ drop and pull cross-sea connection pattern refers to the conduct of drop and pull pattern in Shandong and Liaoning utilizing local vehicles, which perform drop and pull transport in local areas and then park unloaded or loaded trailers in drop and pull centers. Cross-sea transporting vehicles drop the trailer to another region's centers closed to goods supply center through ro-ro ships according to the degree of client demand emergency. The main line transportation between drop and pull centers in Shandong and Liaoning is accomplished by cross-sea transporting vehicles yet local vehicles are responsible for the drop and pull transport among centers and client factories after trailers arrive at the objective area. $\mathrm{M}$ to $\mathrm{N}$ drop and pull connection

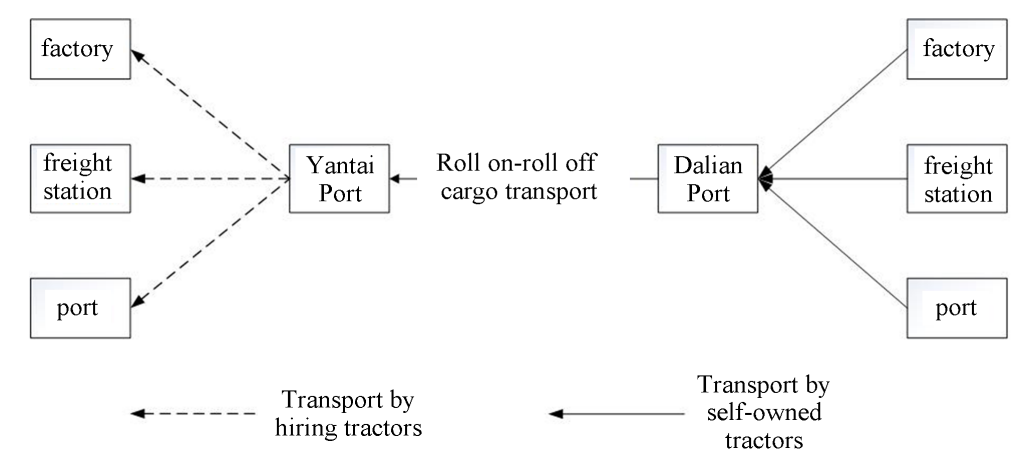

Figure 1. Sketch map of fundamental transport flow path in Bohai Bay. 
pattern has a high requirement to the integrated and unified management of clients, tractors and trailers resources. Consequently it’s difficult to be carried out by a single transport or logistics firm. This kind of pattern, therefore, is suitable for large-scale logistics or transport enterprises of strong resources integration capacity.

Although drop and pull centers don't require high of the hardware during the process, reasonable site selection and layout are of vital significance. The way of setting centers determines the overall transport benefits and the level of services. The amount of specialized drop and pull centers in this project in Shandong and Liaoning is large so the method of site selection influences the general expense level directly. As to this issue, $p$-median model in logistics system planning theory can be adopted to calculate and formulate the optimal solution [9].

Supposing the location and amount of the set of demands (such as clients' factories) are given and there is only one set of candidate center facilities. Requirements are finding a suitable site for each of $p$ centers respectively and designating every demand point a specific center in order to minimize the freight.

The objective function of this issue can be set as:

$$
\min \sum_{i \in N} \sum_{j \in M} d_{i} c_{i j} y_{i j}
$$

Constraint conditions are:

$$
\begin{gathered}
\sum_{j \in M} y_{i j}=1, \quad i \in N \\
\sum_{j \in M} x_{j}=p \\
y_{i j} \leq x_{j}, \quad i \in N, \quad j \in M \\
x_{j} \in\{0,1\}, \quad j \in M \\
y_{i j} \in\{0,1\}, \quad i \in N, \quad j \in M
\end{gathered}
$$

Among which

$$
\begin{gathered}
N=\{1,2, \cdots, n\}, \quad \text { refers to } n \text { deman points } \\
M=\{1,2, \cdots, m\}, \quad \text { refers to } m \text { candidate center facilities }
\end{gathered}
$$

$p$ stands for the sum of center facilities that can be established:

$$
\begin{gathered}
x_{i}= \begin{cases}1, & \text { supposing building centerfacilitieson } j \in M ; \\
0, & \text { other situations. }\end{cases} \\
y_{i j}= \begin{cases}1, & \text { supposing client } i \in N, \text { provided with service by } j \text { center } \in M ; \\
0, & \text { other situations. }\end{cases}
\end{gathered}
$$

As can be seen from the above model, center location and client designation are two most important aspects in the issue of site selection. There are two main algorithms in solving the model subsequently and they are precise genetic algorithms and heuristic genetic algorithms respectively. Here is the case of calculative process in solving p-median model by using one of heuristic genetic algorithms-greedy dropping heuristic algorithm.

Supposing 2 drop and pull centers are planned to be constructed in scheduled specialized logistics work zone. There are 4 candidate sites and 8 existing factories or warehouses' transport orders. The transport cost from candidate sites to different factories or warehouses and the quantity demanded are identified, as is listed in the Table 1.

1) For loop parameter $k=4$, for all four candidate locations, each factory or warehouse is designated to the nearest candidate center, as is shown in the Figure 2.

2) The algorithm selects and drops a candidate center, while satisfying: increment of total costs is the minimum after reappointing the factory previously belonging to the dropped center. For $k=4-1=3$. On figuring out each increment by individually analyzing on four candidate sites, we find that the cost increment is the smallest (equals to 140) when removing the second candidate center. Hence the location of candidate center 2 is eliminated first. 
Table 1. Transport cost and demand schedule.

\begin{tabular}{cccccc}
\hline$c_{i j}$ & \multicolumn{3}{c}{$j$} & $d_{i}$ \\
\hline Distance from factory $\boldsymbol{i}$ to factory $\boldsymbol{j}$ & $\mathbf{1}$ & $\mathbf{2}$ & $\mathbf{3}$ & $\mathbf{4}$ & Demand from factory $\boldsymbol{i}$ \\
\hline 1 & 4 & 12 & 20 & 6 & 100 \\
2 & 2 & 10 & 25 & 10 & 50 \\
3 & 3 & 4 & 16 & 14 & 120 \\
4 & 6 & 5 & 9 & 2 & 80 \\
5 & 18 & 12 & 7 & 3 & 200 \\
6 & 14 & 4 & 4 & 9 & 70 \\
7 & 20 & 30 & 2 & 11 & 60 \\
8 & 24 & 12 & 6 & 22 & 100 \\
\hline
\end{tabular}

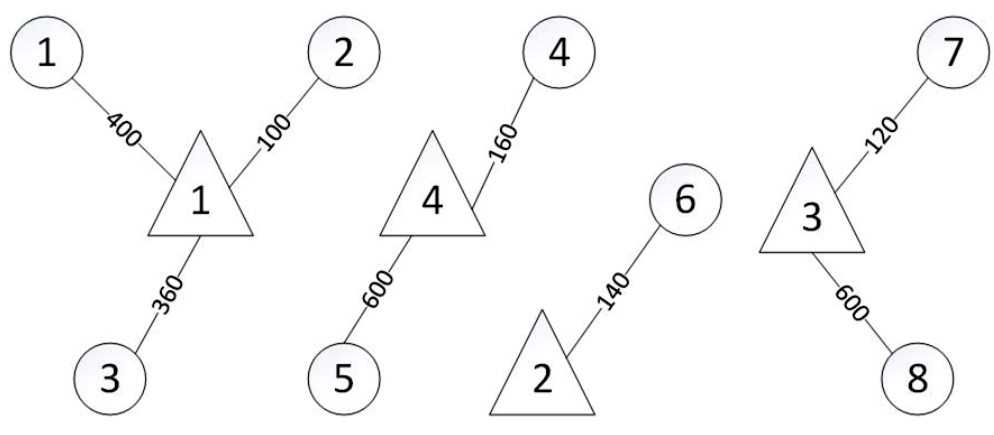

Figure 2. Path diagram of factories or warehouses' nearest candidate centers.

3) The algorithm repeats step (2) until $k=2$. Through calculating the increment while removing location 1,3 , 4 respectively, we find the increment is minimal while taking location 4 away. As a result, drop and pull centers should be established in the location of candidate station 1 and station 3 . The total transport cost by this time amounts to 3740 .

The computed result has the reference value under certain conditions. Combined with matters of fact such as land use planning in practical application, the best location of drop and pull center is obtained eventually.

\subsection{The Idea of Ro-Ro Cargo Transport Channel-"South Bridging-North Rolling"}

The peninsulas where Shandong and Liaoning provinces locate across the sea are vital regions in Bohai economic circle. The development of manufacturing industry and the increase of overseas-funded and joint venture enterprises pave the way for the drop and pull transport. Transport demand gradually shifts from plain increment to elevated quality in the wake of formation of Bohai economic circle. Owing to the obstruct from Bohai Straits, detour problem of highway transportation renders an immense waste. Tongjiang-Sanya main line projected in "Two-longitudinal \& Three-horizontal” arteries by the Ministry of Communications goes through Bohai Straits. How to go across Bohai Straits becomes the biggest problem for its arterial highway transportation. In addition, the integral distribution of ro-ro transport industry is scattered in Bohai Bay at present. As a result, the integrated channel is difficult to be formed smoothly due to comparatively low scale merits.

Aiming at constantly increasing demand of cargo transportation, scholars ever proposed the scheme of "south bridging-north tunneling", which advocated building new channel in Bohai Bay by forging the cross-sea bridge combined with the submarine tunnel. However, the technological content of constructing cross-ocean tunnel is rather high and pre-preparation work can last for at least twenty years. The capital investment into the whole project even exceeds tens of billions [10]. From a long-term point of view, the scheme contains huge invisible benefits. But from the perspective of cargo ro-ro, drop and pull transportation channel between Shandong and Liaoning, the paper argues that short-term transitional scheme of "south bridging-north rolling" is more feasible. That is to construct the highway and bridge connecting to the peninsula in south straits making use of short con- 
struction cycle of the cross-sea bridge and vantage ground of Miaodao Islands, thus replacing the submarine tunnel. Meanwhile, in north of the strait transportation is fulfilled by large-scale ro-ro ships first. The scheme is composed of two aspects in general.

1) The layout of highways is demonstrated as follows. 65 kilometers northward away from Penglai Dengzhou, there are enormous islands can be utilized as the bridge abutment among North Huangcheng Islands. The average water depth of Bohai Straits is only 25 meters while the depth contour in south islands are within 10 meters. Hence the difficulty of bridging is far less than other straits. The seabed is well-conditioned rock geology and there are abundant building material resources on both sides of the strait, which provides easy access to materials handling. Moreover, there is no island in Lao Tieshan Channel 42km northward away from North Huangcheng Islands. The line-shaped bridge whose overall length is about $75 \mathrm{~km}$ can be constructed by segments on a south-north axis [11].

2) The selection process of ro-ro cargo unloading port is as follows. According to the prediction on the total freight volume in Bohai Bay, one to two myriad ton class berths on both south and north sides. Unloading ports must obtain excellent natural conditions such as water depth, wind waves and lands. Shandong can transform the location near Weifang Port into a specialized ro-ro berth or selects South Huangcheng Island as the new ro-ro unloading port. Liaoning can choose Yingkou Port or Huludao Port conducting berth reforming. Both of the ports are of a certain degree of management experience and infrastructure level.

\section{Overall Approaches and Suggestions}

Well-developed and effective land-sea transportation channel between Shandong and Liaoning is a crucial support for Bohai economic circle. Transportation industry has stepped into a new phase of emphasizing both quality and benefits in the wake of economic advancement and expanding market demand. Under such a circumstance it is imperative to construct land-sea channel between Shandong and Liaoning. Networked information, joint rail and water transportation, collaboration of different areas, logistics union and industrial linkage must be set as the focus of work in order to realize the overall objective of making breakthroughs in fields of information platform, experimental unit, regional connection, drop and pull quantity and industrial upgrading [4].

\subsection{Accelerating Construction of Comprehensive Transport Network and Port Rear Channels}

Centering on express freight system and national highway and railway specialized project, through cargo transportation, logistics assignments centralization and seamless connection can be realized by promoting construction of comprehensive logistics hinge in Weifang Binhai District and planning outward transport corridor. Basing on ro-ro cargo system, construction of harbor railway, harbor highway as well as inland river collecting and distributing corridor of major ports in both sides of the strait should be emphasized, thus moving forward ports' rear direct transportation and standardization of shipping routes.

\subsection{Facilitating Cross-Sea Bridge Project \& Forming "South Bridging-North Rolling" Pattern}

The three-step strategy can be adopted here. In the first place, a cooperation organization between Shandong and Liaoning should be formed on Bohai straits cross-sea bridge project for purpose of further discussing its feasibility and preparing for early design. Secondly, a joint project foundation needs to be set up so as to support engineering review or investigation study with seed funding. By the time when the project is implemented, the foundation can be transformed into owner-oriented channel engineering company and obtains bridge franchise from the government. Hence all-round, multi-channel financing at home and abroad can be fulfilled by issuing shares or bonds. Ultimately, authorities and non-governmental figures from two provinces participate jointly in the project planning and attribute resources by regions as well as stages in order to maximize the return from staged investment and reduce financial exposures while assuring phased achievements and benefits.

\subsection{Enhancing Transport Union and Networked Information Building}

For one thing, the project should make use of transport union's information platform to manage cargo supply information and boost ship actual load rate. The stability of bulk cargo supplies can be ensured by actively 
seeking potential big customers and offering specific logistics solutions to them. Meanwhile, the project can attract more enterprises joining in by providing preferential services such as reserving parking space and boarding the ship in advance, thus further discovering bulk drop and pull cargo supplies. For another thing, the building of interactive information network, which exchanges logistics and manufacturing enterprises' database and integrates information of logistics, shipping agents and vehicles, is crucial for applying informationalized dynamic management into the whole logistics process.

\subsection{Integrating Cargo Resources and Establishing Ro-Ro Logistics Centers}

Ro-ro logistics centers are commonly built on both sides of the channel in central regions mainly for integrating cargo resources and realizing scale gathering and distributing. The unified allocation of cargo concentrated transportation and sorting process helps exert car-pooling function. Meanwhile, the center needs to improve service quality by exploiting extending services like information tracking and distributed delivery. Ro-ro logistics centers adopt the form of absorbing distribution station and bring stations' entities and information into logistics central system in order to fulfill cargo supply information sharing, optimized routes and unified allocation, thus reducing overlapping investment in distribution stations and speeding up the turnover of the cargo.

\section{Acknowledgements}

On completing the paper writing, I would like to extend my sincere gratitude to Ms. Chen Juan and Mr. Liu Yongsheng from Business School of Beijing Wuzi University for their patient instruction and precious suggestions.

\section{References}

[1] Zhang, J.X. (2013) Analysis and Prospection on Bohai Drop and Pull Logistics Transport. Economic Outlook the Bohai Sea, 6, 17-19.

[2] Huang, Q. (2009) Research on Promoting the Construction of the Yangtze River Comprehensive Transportation Corridor. China Water Transport, 9, 4-5.

[3] Li, Y., Li, Z.X. and Yan, P. (2012) Assessment on Operational Risk of Yantai Swing Hanging and Ro-Ro Transport. Journal of Dalian Jiaotong University, 33, 34-38.

[4] Xue, H.L. (2012) Investigation on Ideological Work of Drivers and Attendants the State-Owned Enterprise of Road Passenger Transport Company. Transportation Enterprise Management, 27, 3-5.

[5] Li, X.G. and Xue, N. (2010) Logistics Cooperation Mechanism of Bohai Economic Zone and Northeast Asia Economic Circle. Northeast Asia Forum, 1, 9.

[6] Zhao, Y.B. (2008) Research on the Rolling Transportation Market and Its Developing Trends between Yantai and Dalian. Dalian Maritime University, Dalian.

[7] Lin, N. (2003) Logistics System Planning_Modeling and Case Analysis. China Machine Press.

[8] Zhang, H. (1998) Investigation on Construction of Bohai Straits Cross-Sea Highway Transport Corridors. Northeastern Highway, 21, 76-80.

[9] Zhao, S.F. and Li, X.G. (2013) Measures on Sustainable Development of Swing Hanging Transport in Shandong Peninsula Blue-Economic Zone. Containerization, 24, 1-24.

[10] Lv, Y.C., Kong, W.G. and Guo, L. (2006) Feasibility Research on Drop and Pull Transport for Ferrying in Bohai Gulf. Navigation of China, 4, 69-73.

[11] Lin, R.Q. and Liu, Z. (2009) Research on Measures of the Construction of Taiwan Strait Comprehensive Transportation Corridor. Comprehensive Transportation, 5, 33-37. 